Inge's standards, probably should be listed on the novel's title page. Only in very insignificant ways was she ever able to restore the punctuation of her manuscript.

Modern editors of Jane Eyre, taking Brontë's letters of 24 and 29 September as a clear statement of intention, have made the grave mistake of using the first edition rather than the fair copy as their copy-text, as Bruce Harkness decisively argued in a review of the Clarendon edition (Nineteenth-Century Fiction 25 [1970]: 355-69) and as I exemplified in my "Pointing Theory and Some Victorian Practices" (Yearbook of Research in English and American Literature 4 [1986]: 97134, esp. 114-22). The result is that all readers except the few who have studied the manuscript have seen Charlotte Brontë or Jane Eyre (to borrow Inge's analogy) attired in the most grotesque Victorian garb imaginable and not in the relatively simple, neat, and appealing frock supplied by the author. Indeed, the thousands of changes made to the fair copy (Inge illustrates how a single comma can be noteworthy) do accumulate in importance and do help to govern tone, emphasis, pace, and certainly nuances.

Though I am not prepared to cite other instances like Jane Eyre, I suspect that the novel is not an anomaly and that other texts are equally in need of decollaboration. In any case, Charlotte Brontë, no longer obscure and powerless, deserves the kind of collaboration that she could not command in 1847 . I would welcome an experienced editor who could collaborate with me to give the world the Fair Copy Edition, a readable edition suitable for both scholars and students.

Daniel P. Deneau Fairhope, AL

Reply:

Daniel P. Deneau makes many sound points. It is not my intention, however, to suggest that the collaborative process in publishing that I describe necessarily benefits works of literature. As I note, “It doesn't always work this way, but it works often enough to have made some publishing firms financially solid and some authors wealthy" (625).

The case of Jane Eyre is an exceptional one that I doubt is widely representative, and if things are as bad as Deneau suggests, one wonders why Charlotte Brontë so freely acceded to the punctuation provided by the publisher. She may have been an "unknown [...] and powerless woman," but did she have to be so enthusiastic? It is true she was not in the position of Mark Twain, who owned his own publishing firm and could wire the managing editor about preparing A Connecticut Yankee in King Arthur's Court for publication, "[Y]esterday Mr. Hall wrote that the printer's proof-reader was improving my punctuation for me, \& I telegraphed orders to have him shot without giving him time to pray" (A Connecticut Yankee in King Arthur's Court, ed. M. Thomas Inge [Cambridge: Cambridge UP, 1997] xix).

It is interesting to note what Deneau calls for at the conclusion of his letter-someone with whom to collaborate on a new edition. A lot of important things do seem to get done most easily with more than one hand at work.

M. Thomas Inge Randolph-Macon College

\section{The Tone of Debate in the Forum}

\section{TO THE EDITOR:}

Your concern with the paucity of quality submissions to PMLA finds a partial response in Linda Hutcheon's timely Presidential Address (116 [2001]: 518-30), in which Hutcheon and other scholars explore alternatives to the "adversarial academy." I suggest that PMLA itself appears as a particularly adversarial forum, discouraging many, particularly junior, scholars from sending you articles.

Some of the letters that are published in the PMLA Forum exhibit the very culture of negative critiquing to which Hutcheon tries to find alternatives. We all know that destructive opposition can make or break professional identities and on occasion do lasting damage to the "loser's" con- 
fidence. No, we are not cowards. Some of us who have seen for ourselves the fluid boundary between verbal and other forms of violence prefer not to position ourselves on that continuum at all. Instead of continuing to devour one another's work with vulturine rapacity while occasionally for appearances' sake stopping to bemoan our culture of combat, many scholars prefer to seek out more productive dialogic spaces. Since to publish in PMLA can mean-as the Forum exchanges show us - to lay oneself open to the most vituperative kind of critique, I do not find it surprising that much good work is being directed to different communities of readers.

Ironically, in the very PMLA issue containing Hutcheon's plea for a more integrative approach to others' work, there are some particularly scathing exchanges in the Forum: three letters written in response to two recent articles, with the replies of those articles' authors. The writers of the letters show little or no respect for their constructed "opponent's" point of view, eliding true engagement in favor of condescension and, once in a while, unnecessary personal slurs. While it was not surprising, knowing their work, that two of the scholars involved in particular should publicly disembowel each other, the Forum is nevertheless read by many other readers who are discomfited by the tone set by such exchanges. Disagreement is one thing. Mudslinging is another, and I think it should be kept between the individuals involved. They can find each other's e-mail addresses if necessary. PMLA should publish only thoughtful, responsible critiques in the Forum, applying its editorial standards to this section of the journal as to everything else.

It all makes for good reading, but although demeaning rhetoric is fun and witty, it sadly masks the writer's failure to engage the other's opinions or work substantially, even while disagreeing. Such exchanges serve only to convince me, a relative newcomer to the profession seeking publication possibilities, to send my articles elsewhere. Not that I eschew positive contention-constructive or collaborative criticism is the backbone of our profession-but I would rather not set myself up for verbal violence whose only goal is the aggrandizement of someone else's professional ego. I am sure this will happen anyway at some stage, and I am sure I will even participate in it myself despite my best intentions, but I would rather not hurry along that encounter.

This dynamic is particularly uncomfortable for nontenured scholars and graduate students. Not only could our work (I am aware that this is a worst case) be publicly damaged by caprice and malice at a time in our careers when we truly need positive feedback and a modicum of self-confidence at the end of the day, but we do not yet have the status to reply in kind, with a cheeky risposte, should we wish to. Many of us do not wish to; that is not the point. The point is the gesture of exclusion from a certain type of discourse. Tenure in this case acts as a license to behave badly in public that many of the nontenured feel we do not have. The idea that anyone even at the bottom of the ladder can publicly offer unfettered criticism to anyone we disagree with and not suffer negative professional consequences is naive; politics in academe are just as governed by ego jostling as anywhere else. I imagine that independent scholars feel likewise intimidated by the tone of the Forum exchanges.

Not that we should all just get along (this is the fantasy of people who are not paying attention), but I do think, no doubt naively, that we should behave better when we disagree. Even if we have no respect for an opinion, we can at least treat it with respect. I would like to think that part of the study of the humanities is knowing how to have, well, humane conversations about the relation of our work to others'.

I am aware that I am, by taking an adversarial position against adversarial positions, merely repeating the same kind of oppositional dialogue that I purport to challenge. I should, by my own rules, have respect even for the anger I dislike in Forum letters: it too comes from somewhere and has its reasons. My contradictions show that I too need to treat with respect an opinion I disagree with. It is one of the hardest lessons, but in today's world it is particularly 
incumbent on us to learn it, and we should be up to the task. I think we're smart enough.

Louisa Mackenzie University of Washington, Seattle

\section{TO THE EDITOR:}

For the first time ever, I got a good laugh from PMLA. In Edward W. Said's Forum reply (116 [2001]: 656-57), he says that Roger Shattuck "has no grasp of the facts" and is "[p]oorly informed about elementary matters," that Shattuck "complain[s] petulantly," that Shattuck is "ignorant," that Eurocentrism is a "subject about which Shattuck shows that he knows next to nothing," that Shattuck's book is a "dismayingly censorious work," that Shattuck "speaks dismissively," that Shattuck has descended to "McCarthyism," that Shattuck's ideas are "dyspeptically affirmed," that Shattuck has a "closed mind," and that Shattuck suffers from a "puritanical rejection of the world we live in."

I got my laugh when, near the end of his reply, Said accuses Shattuck of "descend[ing] to such a level of name-calling”!

Sherry Lutz Zivley University of Houston, University Park

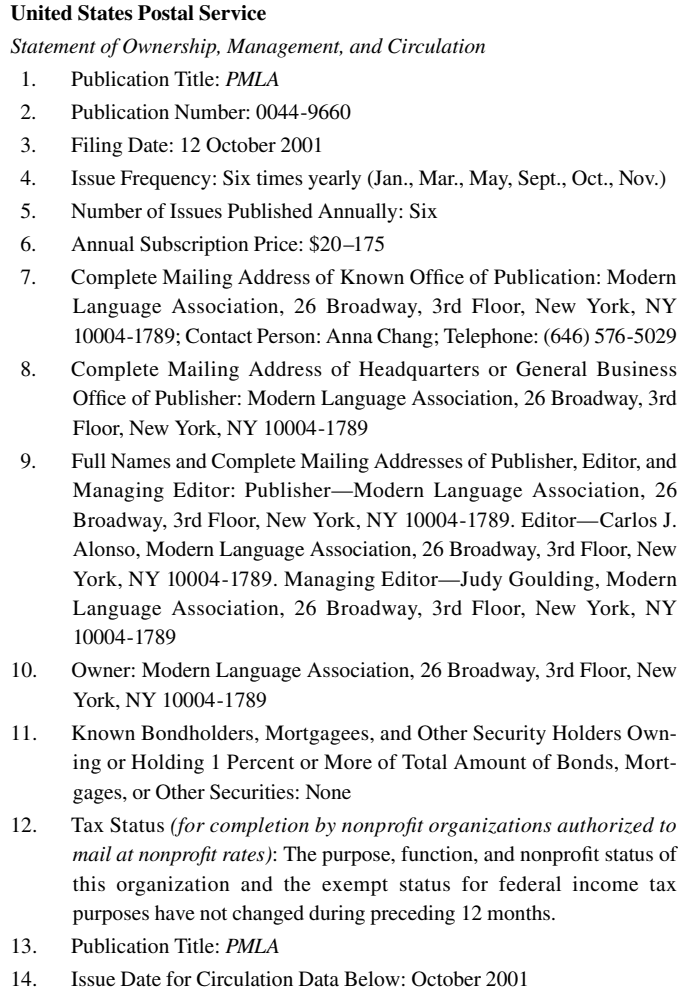

15. Extent and Nature of Circulation

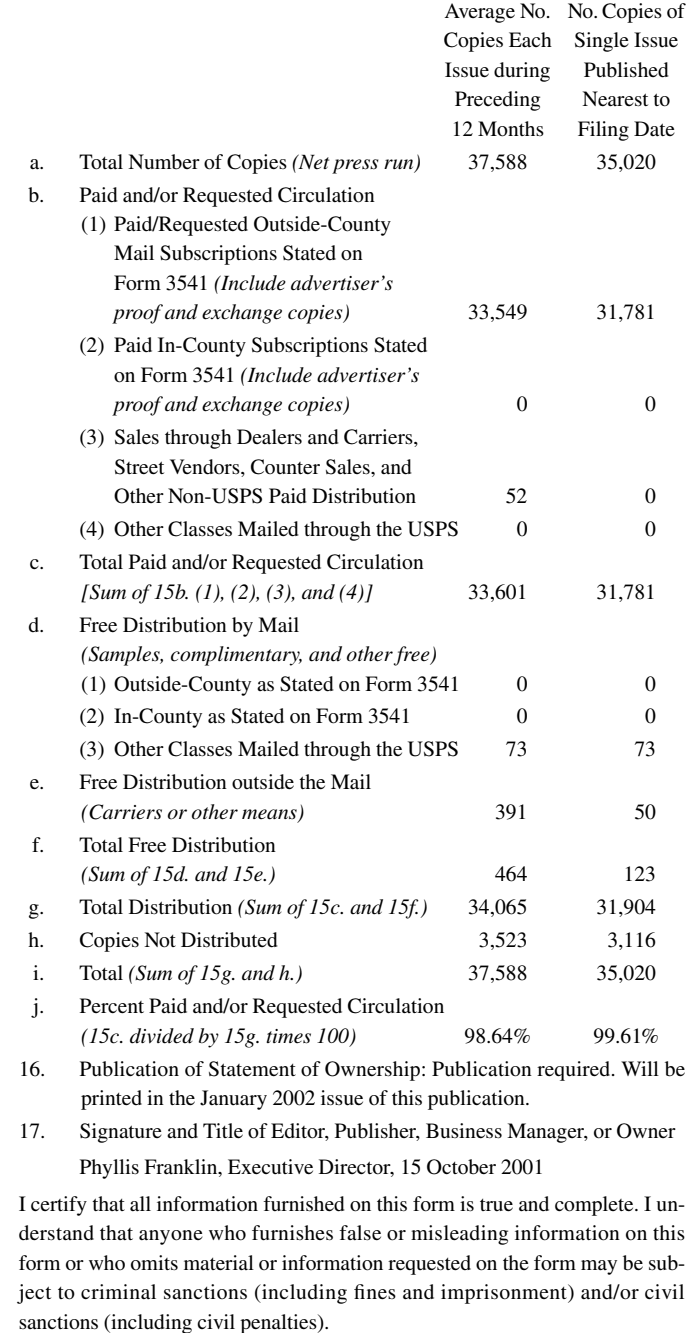

